SHORT COMMUNICATION

\title{
The first confirmed case of Diphyllobothrium latum in Brazil
}

\author{
FLN Santos*/+, LB de Faro
}

Setor de Parasitologia, Centro de Medicina Laboratorial, Av. Antônio Carlos Magalhães 4009, sala 5, 40280-000 Salvador, BA, Brasil
*Centro de Pesquisa Gonçalo Moniz-Fiocruz, Salvador, BA, Brasil

Diphyllobothriasis is an infection of the small intestine by the broad tapeworm Diphyllobothrium $\mathrm{sp}$. The associated symptomatology is nonspecific, but megaloblastic anemia is a well-described complication. Although the infection is common in temperate regions, descriptions in South America have so far been limited to Chile, Peru, and a few cases in Argentina. This paper presents the first confirmed Brazilian case of diphyllobothriasis. A 29-years-old woman living in Salvador (state of Bahia) apparently acquired the infection from eating sushi. The diagnosis was based on fecal examination that revealed a large quantity of operculated eggs. A single dose of praziquantel $(600 \mathrm{mg})$ was sufficient to cure the infection.

Key words: Diphyllobothrium latum - infection - Brazil

The growing popularity of uncooked or raw seafood in Brazil has resulted in the proliferation of certain human parasitic infections. Diphyllobothriasis, an infection of the small intestine by the broad tapeworm Diphyllobo-thrium sp., is an ictic zoonosis acquired by humans and other mammals (e.g. bears, foxes or dogs) through ingestion of raw, undercooked or smoked fish (Essex \& Magath 1931). This worm is the longest human parasite known $(10 \mathrm{~m}$ long or more) and may live for up to 25 years in the host (Leiper 1936). There are often no clinical symptoms associated with infection, apart from eosinophilia. However, in a proportion of cases there is abdominal pain, weight loss, anorexia, nausea, vertigo, and vomiting. Anemia due to B-12 deficiency has been described in cases of prolonged infection (Osorio et al. 1974, Vuylsteke et al. 2004).

This infection is common in regions with cold water lakes, such as Europe (Dupoy-Camet \& Peduzzi 2004), Asia (Lee et al. 2001), and North America (Hanlon et al. 1982). In South America, the infection is common in Chile and Peru (Reinhard \& Urban 2003) and there have been sporadic reports in Argentina (Semenas \& Ubeda 1997, Semenas et al. 2001), none Brazilian cases of diphyllobothriasis have been published in scientific literature. This infection is not autochthonous in Brazil.

Case report - A 29-years-old woman living in Salvador (state of Bahia, Northeast region of Brazil) presented to out-patient clinic on September 2004 with complaints of gastrointestinal discomfort, including several days of abdominal pain, diarrhea, colic, and nausea. No vomiting or fever was reported. Her clinical history revealed that she had eaten raw fish (sushi) with her family some days before. The following laboratory tests were performed:

\footnotetext{
${ }^{+}$Corresponding author. E-mail: fneves@cpqgm.fiocruz.br Received 24 March 2005

Accepted 5 August 2005
}

complete blood count, blood biochemistry, and fecal examination (thick smear method, three samples taken on alternating days). The serum chemistries were all within normal ranges, and the hematological examination revealed: hemoglobin 14.0, hematocrit $43.1 \%$, WBC 9.42 $10^{3} / \mu 1$, platelet $37010^{3} / \mu 1$, MCV $93.1 \mathrm{fL}$, MCH $30.2 \mathrm{pg}$, total eosinophil count $4.5 \%$. The fecal examination revealed a large quantity of operculated eggs (Figure). None proglotid forms were found. A single dose of praziquantel $600 \mathrm{mg}$ was given, and the patient's feces were found to be egg-free after one month.

The cycle of this parasite is complex and involves several hosts (Dupoy-Camet \& Peduzzi 2004). The fertilized eggs are released into the intestine. In the water, they mature within eight to twelve days at a water temperature of $16-20^{\circ} \mathrm{C}$, and yield coracidium larvae that are ingested by a zooplanktonic copepod crustacean. About 40 copepod species of the Eudiaptomus or Cyclops genus are likely to be first intermediate hosts. The free-living stages emerge through the operculum and are ingested by crustaceans, where they lose their cilia and penetrate through the gut wall into the coelum. There, they take up nutrients and develops into the procercoid stage with a cercomer. They remain in the copepod until they are eaten by the second intermediate host, usually a Pike or salmon. After infecting the secondary host, the parasite penetrates the gut, loses its cercomer and makes its way to the muscle where it becomes a plerocercoid. If the second intermediate host is eaten by a larger predatory fish, then the plerocercoids migrate to the muscle of this fish. The plerocercoid can be up to a few centimeters in length, and is usually coiled within the muscle cell. When the plerocercoids are ingested by the definitive host, they pass through the stomach and the scolex becomes embedded in the mucosa of the small intestine and develops rapidly, producing eggs within 10-14 days.

Diphyllobothriasis is typically an asymptomatic condition, but many symptomatic cases of human infection go largely unnoticed because of the nonspecific symptoms such as nausea, intestinal discomfort, and diarrhea. However, in some cases, megaloblastic anemia develops as a result of vitamin B12 deficiency induced by malabsorp- 


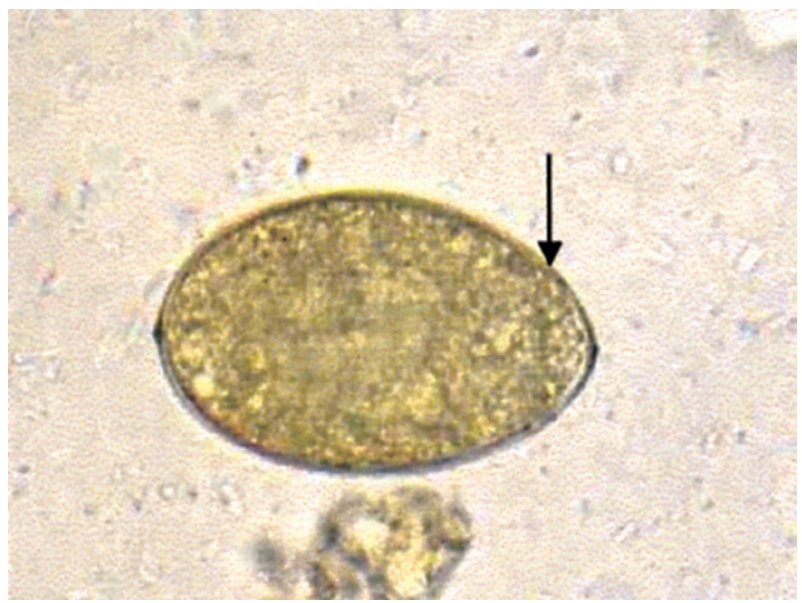

Fertilized egg from Diphyllobothrium latum encountered in feces of a 29 -years woman living in Salvador (state of Bahia, Northeast Brazil). The eggs are ovoid, with an operculum at one end and a knob at the other (arrow), and measure 58-76 $\mathrm{mm}$ in length and 40-51 $\mathrm{mm}$ in diameter.

tion of B12 by the host (Osorio et al. 1974, Vuylsteke et al. 2004). The parasite cleaves and selectively takes up B12, competing with the host for the vitamin. Our patient presented only nonspecific symptoms of this infection, and the absence of the megaloblastic anemia was attributable to the short space of time between infection and detection of the parasite.

Diagnosis of this infection is based on identification of fertilized, operculated, and ovoid eggs in the stool by thick smear method. The eggs possess a thick outer layer, and occasionally present a knob opposite to the operculum (Figure). Usually, a large quantity of eggs (up to 1 million) is produced each day. The eggs measured $55-75$ by $40-60$ $\mu \mathrm{m}$. Other species of Diphyllobothrium can also infect humans, but $D$. latum eggs are similar in size to those identified in the patient. According to Baer et al. (1967) the eggs of D. pacificum, for example, are thick-shelled, operculated, measuring 40-60 $\mu \mathrm{m}$ in lenght and 36-40 $\mu \mathrm{m}$ in diameter; they are thus considerably smaller than those of $D$. latum with which they cannot be confused. The size of D. latum eggs is $58-76 \mu \mathrm{m}$ in lenght and $40-51 \mu \mathrm{m}$ in diameter.

This is a worldwide disease that affects people near fresh water and appropriate intermediate hosts. Areas where consumption of raw/precooked fish is popular tend to have endemicity. In South America, Chile and Peru are the most affected countries (Semenas \& Ubeda 1997, Semenas et al. 2001, Reinhard \& Urban 2003). This is the first case from Brazil described in the scientific literature. The only potential source of infection that the 29 year-old woman reported was eating sushi acquired in a supermarket chain in Salvador.
There is a large number of possible drugs available to treat this disease, and the two main ones used are niclosamide and praziquantel, both of which are highly effective. A single dose of praziquantel $(600 \mathrm{mg})$ was given, and was found to be adequate for curing the patient. The control cure of this infection is absence of eggs in the feces one month after treatment.

Perhaps the infection rate of $D$. latum in humans will increase with the increasing consumption of raw (sushi, sashimi) and smoked ictic meat, with subsequent negative economic and health impacts on the Brazilian population. However, a combination of improved sanitary surveillance of imported fish (salmon and others) and increased emphasis on sanitary practices in restaurants appears to be the best strategy for controlling and impeding the installation of this helminth in Brazil. Other effective control measures include cooking fish properly and freezing the fish below $20^{\circ} \mathrm{C}$ for a minimum of 7 days or below $35^{\circ} \mathrm{C}$ for $15 \mathrm{~h}$ before ingestion.

\section{REFERENCES}

Baer JG, Miranda CH, Fernandees RW, Medina TJ 1967. Human diphyllobothriais in Peru. Zeitsch Parasit 28: 277-289.

Dupoy-Camet J, Peduzzi R 2004. Current situation of human diphyllobothriasis in Europe. Eur Monthly 9: 5-6.

Essex HE, Magath TB 1931. A comparison of the viability of ova of the broad fish tapeworm, Diphyllobothrium latum, from man and dogs: its bearing on the spread of infestation with parasite. Am J Hyg 14: 698-704.

Hanlon JT, Angle MA, Ebbert PJ 1982. Diphyllobothrium latum infection in a North Carolina couple. South Med J 75: 1431-1432.

Lee KW, Suhk HC, Pai KS, Shin HJ, Jung SY, Han ET, Chai JY 2001. Diphyllobothrium latum infection after eating domestic salmon flesh. Korean J Parasitol 39: 319-321.

Leiper RT 1936. Some experiments and observations on the longevity of Diphyllobothrium infections. J Helminthol 14: 127-130.

Osorio G, Daiber A, Donckaster R, Ubilla M, Con I, Anguita T, Pinto R 1974. Severe megaloblastic anemia due to Diphyllobothrium latum. First case identified in Chile. Rev Med Chil 102: 700-703.

Reinhard K, Urban O 2003. Diagnosing ancient diphyl-lobothriasis from Chinchorro mummies. Mem Inst Oswaldo Cruz 98(Suppl.1): 191-193.

Semenas L, Ubeda C 1997. Difilobotriais humana en la Patagonia, Argentina. Rev Saúde Pública 31: 302-307.

Semenas L, Kreiter A, Urbanski J 2001. New cases of human diphyllobotrhriasis in Patagonia, Argentina. Rev Saúde Pública 35: 214-216.

Vuylsteke P, Bertrand C, Verhoef GE, Vandenberghe P 2004. Case of megaloblastic anemia caused by intestinal taeniasis. Ann Hamatolol 83: 487-488. 